\section{Elementary Physics}

For Medical, First Year University Science Students and General Use in Schools.

By Prof. G. Stead. Sixth edition. Pp. xiv +562 . (London: J. and A. Churchill, Ltd., 1940.) 12s. $6 d$.

DROF. STEAD'S book is primarily intended for the use of medical students and first-year university students, though the author expresses the hope that it will be found useful for School Certificate and Higher School Certificate candidates. In a single book covering such a wide field, it is not possible to treat the various topics as fully as perhaps one would wish and it is intended that the book should be used in connexion with a course of lectures with practical demonstrations. So far as Higher School Certificate work is concerned, this plan would be necessary. In the main, the book is up to date; it seems a pity, however, that the more convincing method of using actual beams of light instead of pins in verifying laws in connexion with mirrors and lenses is not advocated. Also in a modern text-book surely less space should be devoted to the 'shadow' and 'grease spot' photometers, and more attention paid to modern instruments to bring the subject into line with modern practice.

The book is excellent in its way; the diagrams are good and plentiful, and so far as space will allow the facts are presented clearly. It is, however, definitely a book for specific examination purposes, and apart from the stress made on medical applications, there is little attempt to correlate physical principles with everyday life; probably for a single text-book too much has been attempted.

\section{First Course in Theory of Numbers}

By Prof. Harry N. Wright. Pp. vii +108. (New York : John Wiley and Sons, Inc. ; London : Chapman and Hall, Ltd., 1939.) 12s. net.

$\mathrm{W}$ HAT is the minimum knowledge of the theory of numbers that every mathematician should have ? The question must be elaborated. "Should", because ignorance is likely to detract from his efficiency whatever his own field may be ? Then he needs very little: the Euclidean algorithm and its direct consequence in the existence of identities of the form $a x-b y=1$; nothing at all about continued fractions, if the current fashion is a safe guide. "Should", in order to discover whether the subject makes any appeal to him ? Then add the elements of linear congruence, and a few classical theorems such as Fermat's. "Should", if he cares about being wellread in pure mathematics generally ? Then include simple continued fractions and the law of quadratic reciprocity.

Prof. Wright's book is a college course, appropriate in scope to the last class of reader, and with a satisfying unity, but rather expensive regarded as a substitute for four or five chapters of a text-book on algebra. The author has succeeded in infusing his enjoyment of the subject into a sound exposition. Confusion on the eastern side of the Atlantic is almost inevitable: this bookwright is not Prof.' Hardy's collaborator in the same domain. E. H. N.
Calculations of Quantitative Analysis

By Prof. Carl J. Engelder. Pp. viii+174. (New York : John Wiley and Sons, Inc.; London: Chapman and Hall, Ltd., 1939.) 12s. net.

7 HIS book, which is up to the English Interforward account of the theory underlying the calculations in quantitative analysis. The text is illustrated by a large number of worked-out problems, and each of the fifteen chapters concludes with original calculations for the student to work out for himself. Answers are only given to the odd-numbered problems, since these are intended for home-work, but those to the even-numbered problems can be obtained on application to the publisher.

The book is divided into four parts. The first part is devoted to general considerations such as the use of logarithms and the methods of designating the strength of solutions. The calculations in volumetric work are considered in the second part, and this includes the calculation of values in acid-base titrations. Part 3 is devoted to gravimetric analysis and includes a chapter on the solubility product principle. The fourth part deals briefly with the application of analytical data, as for example, the calculation of atomic weights.

The subject-matter in these four parts is generally sound and up to date, though the statement (p. 58) that salts of the sodium chloride type are ionized 80 per cent or more in $0.1 \mathrm{~N}$ solutions is not in keeping with modern theory. Similarly, it is confusing to find a calculation (p. 129) on the hydrogen ion concentration of a mixture of $0.5 \mathrm{M}$ acetic acid and $0.3 M$ sodium acetate in which an allowance is made for the 78 per cent ionization of the salt.

At the end of the book, in addition to an index and logarithm tables, there is a large number of tables of physical properties, such as the specific gravities of acids and alkalis and the solubility of salts, which should prove very useful in the laboratory.

A. C. C.

\section{Organic Chemistry}

By Dr. F. Sherwood Taylor. Third edition. Pp. xi+588. (London : William Heinemann, Ltd., 1940.) $10 s$. $6 d$.

R. TAYLOR has established a reputation as a writer both of text-books and more popular works on science, and he is thus able to put a little more feeling into his descriptive organic chemistry than is customary-some of the compounds seem to have life and uses and to be something more than colourless crystalline compounds having the formulæ indicated. It is a task to get all organic chemistry into 500 pages; the same number of specialized monographs would scarcely do it. Yet something has to be provided to enable the student to beat the examiner. The book has a biological bias as is to-day proper: it contains the essential significant facts about the commoner organic compounds, the present. ation is clear and we have no hesitation in recommending it as in many ways superior to its competitors.

E. F. A. 